УДК 550.41

\title{
ТЕРМОДИНАМИЧЕСКОЕ МОДЕЛИРОВАНИЕ РАСПРЕДЕЛЕНИЯ РЗЭ+Ү ПО ФОРМАМ В ОХЛАЖДАЮЩИХСЯ БОГАТЫХ СУЛЬФАТНОЙ СЕРОЙ ФЛЮИДАХ
}

\author{
Широносова Галина Петровна', \\ shiron@igm.nsc.ru \\ Прокопьев Илья Романович ${ }^{12}$, \\ prokop@igm.nsc.ru

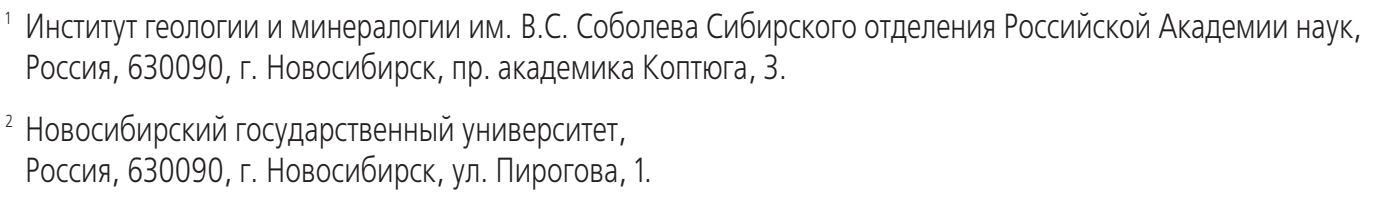

Актуальность работы обусловлена тем, что исследование фракционирования лантаноидов и иттрия (РЗЭ+Ү) по формам в хлоридно-сульфатно-карбонатных флюидах в щелочных и слабокислых условиях позволяет оценить влияние параметров рудообразующей среды на транспорт редкоземельных элементов в процессе рудогенеза в пределах карбонатитовых рудно-магматических систем.

Цель: оценить вклад фторо-, хлоро-, карбонат-бикарбонатных, сульфатных и фосфатных комплексов РзЭ+Ү в транспорте и процессе рудоотложения гидротермальными флюидами в слабокислых и слабощелочных условиях при температуре $500-100^{\circ} \mathrm{C}$ и давлении 2000-125 бар.

Методы: расчетное моделирование воздействия гидротермальных флюидов на монацит и кальцит с использованием пакета HCh (разработчик Ю.В. Шваров). Для установления состояния равновесия в алгоритме программы использован метод определения минимума свободной энергии Гиббса системы (программа GIBBS) в комплексе с термодинамической базой UNITHERM, дополненной экспериментальными результатами для РЗЭ-комплексов и минералов.

Результаты. Приведено распределение РЗЭ+Ү по формам в охлаждающихся хлоридно-сульфатно-карбонатных высококонцентрированных слабокислых и слабощелочных флюидах. Показано, что в слабощелочных условиях лидирующими оказываются нейтральный и второй гидроксокомплексы вплоть до $200{ }^{\circ} \mathrm{C}$. При понижении температуры до $100{ }^{\circ} \mathrm{C}$ РЗЭ+Y обнаруживаются в форме карбонатного и второго фторокомплекса $(L n, Y) F_{2}^{+}$. В слабокислых условиях резко преобладают сульфатные комплексы лантаноидов во всем исследованном интервале параметров флюида. При возрастании номера лантаноида (особенно для тяжелых РЗЭ) усиливается роль фторидных комплексов с уменьшением вклада сульфатных комплексов.

\section{Ключевые слова}

РЗЭ+Y, гидроксо-, фторо-, хлоро-, сульфатные, фосфатные комплексы,

распределение по формам во флюиде, богатый сульфатной серой флюид, термодинамическое моделирование.

\section{Введение}

По мере усовершенствования технологий редкоземельные элементы (РЗЭ) становятся важными товарами из-за их использования в различных высокотехнологичных отраслях. В земной коре РЗЭ обычно встречаются в следовых концентрациях, тогда как их экономические месторождения обычно связаны с карбонатитами и щелочными магматическими системами. Важными примерами месторождений РЗЭ являются Вауап Оbo в Китае [1], Странное Озеро и Нечалачо в Канаде [2, 3], Маунтин Пасс [4] и Бир Лодж в США [5]. Многочисленные исследования показали важность гидротермальных процессов для мобилизации РЗЭ на поздних этапах магматической эволюции карбонатитовых и щелочных систем. Теперь почти повсеместно общепринято, что гидротермальные флюиды мобилизуют РЗЭ и в некоторых случаях концентрируют их до экономического уровня [1, 2, 6-8]. Поэтому становится все более очевидным, что оценка процессов, концентрирующих РЗЭ до экономических уровней в земной коре, требует количественного понимания факторов, ответственных за их мобильность и концентрацию в гидротермальных растворах.
Распределению РЗЭ во флюидах в гидротермальных условиях посвящен целый ряд экспериментальных работ и публикаций, в которых приводятся результаты термодинамического моделирования. Cреди первых наиболее значимы работы А.А. Мигдисова с соавторами [9-12], в которых не только даны экспериментально определенные константы устойчивости отдельных хлоро-, фторо- и сульфатных комплексов, но и анализ распределении ряда лантаноидов при повышенных температурах. В работе [13] приведены результаты моделирования, показывающие комплексообразование $\mathrm{Ce}, \mathrm{Y}$ и $\mathrm{Zr}$ в зависимости от $\mathrm{pH}$ при 150 и $400{ }^{\circ} \mathrm{C}$ в присутствии карбонат-содержащей породы и флюида с концентрацией $0,2 \mathrm{~m} \mathrm{H}_{3} \mathrm{PO}_{4}$, $0,4 \mathrm{~m} \mathrm{HF}$ и 0,4 m HCl. Е.П. Пери и А.П. Гизи в одной из последних работ [14] приводят результаты численного моделирования комплексообразования в простых водно-углекислых флюидах при гидротермальных температурах $\left(\sim 100-400{ }^{\circ} \mathrm{C}\right)$ и давлениях до 1 кбар. Ими показано распределение по формам церия, неодима и эрбия в интервале 0,5 и 20 вес. \% $\mathrm{NaCl}$ в зависимости от температуры (100 ppm PЗЭ, $\mathrm{CO}_{2}$ 0,1 и 50 г кальцита), а также в системах с $\mathrm{CO}_{2}^{-}$ $\mathrm{NaCl}$ в зависимости от $\mathrm{pH}$. В отличие от наших расчетов в их моделях не учитывалось наличие $\mathrm{F}, \mathrm{P}$ и $\mathrm{S}$. 
В настоящей работе рассматривается распределение по формам всех 14 лантаноидов + Ү в высококонцентрированном охлаждающемся хлоридносульфатно-карбонатном флюиде с подчиненными концентрациями в нем фторида и сульфидной серы, воздействовавшем на кальцит (источник Са) и монацит (в форме идеального твердого раствора, в качестве источника РЗЭ и фосфора). Соотношение равновесных минералов макросистемы и РЗЭ-содержащих представителей микросистемы (с возможностью дополнительного образования идеальных твердых растворов РЗЭ+флюорита, РЗЭ-фторапатита и ксенотима), а также коэффициенты распределения РЗЭ между минералами и флюидом было представлено в наших предыдущих публикациях $[15,16]$. В работе [15] детально описаны условия проведения расчетов и источники термодинамических данных. В частности, для хлоро-, фторои сульфатных комплексов РЗЭ использованы термодинамические характеристики, полученные экспериментальным путем при повышенных температурах $[10,12]$, но для водных гидроксокомплексов, бикарбонатных, карбонатных и фосфатных комплексов РЗЭ данные получены на основании экстраполяции из экспериментов при температуре окружающей среды [17]. В исследовании [18] при обработке спектральных данных обнаружено, что в интервале значений $\mathrm{pH}$ от 8 до 11 в изучаемых растворах присутствуют моногидроксид лантаноидов $\operatorname{Ln}(\mathrm{OH})^{2+}$ и комплексные формы со стехиометрией $\mathrm{Ln}(\mathrm{OH})_{2}{ }^{+}$и $\mathrm{Ln}(\mathrm{OH})_{3}{ }^{0}$, четвертый гидроксокомплекс не обнаружен, поэтому в настоящей работе мы исключили его из числа возможных РЗЭ форм.

\section{Результаты моделирования}

Термодинамические расчеты проведены с использованием программного пакета $\mathrm{HCh}[19,20]$. На рис. 1 приведены кривые равновесных концентраций макрокомпонентов системы (S, F, Ca и $\mathrm{P})$ в

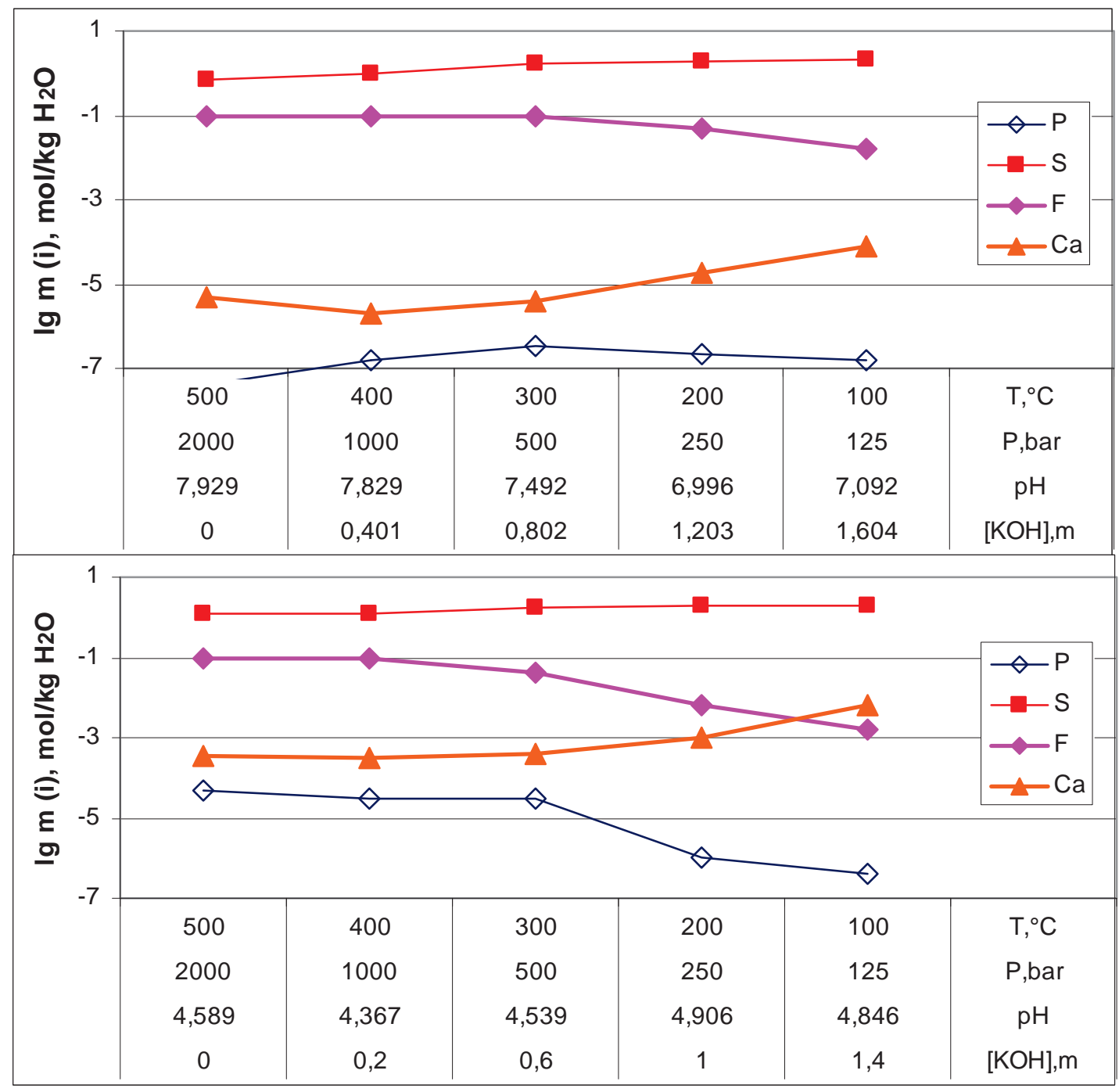

Рис. 1. Концентрации компонентов макросистемы в равновесных слабощелочном и слабокислом хлоридно-сульфатно-карбонатных охлаждающихся флюидах

Fig. 1. Concentrations of the macrosystem components in equilibrium weakly alkaline and weakly acid chloride-sulfate-carbonate cooling fluids 
зависимости от параметров хлоридно-сульфатнокарбонатных охлаждающихся флюидов для слабощелочного (верхний рисунок) и слабокислого (нижний рисунок) вариантов. Хорошо видно, что равновесная концентрация серы практически не зависит от кислотно-щелочных условий. Это связано с тем, что в обоих вариантах концентрацию серы контролирует преобладающий в равновесной твердофазовой ассоциации осаждающийся тенардит $\left(\mathrm{Na}_{2} \mathrm{SO}_{4}\right)$ [15]. В слабокислых условиях дополнительно присутствуют ангидрит $\left(\mathrm{CaSO}_{4}\right)$ и элементарная сера, но они не играют существенной роли, т. к. образуются в подчиненных количествах [15]. Второй по значимости в равновесных флюидах оказывается концентрация фтора, которая в высокотемпературной области остается на исходном уровне $(0,1 \mathrm{~m}$, здесь и далее $\mathrm{m}$ означает г-моль/кг $\mathrm{H}_{2} \mathrm{O}$ ), а начиная с $300{ }^{\circ} \mathrm{C}$ она уменьшается благодаря осаждению равновесного флюорита, причем в слабокислых условиях флюорит выпадает в больших количествах, что приводит к более резкому уменьшению концентрации фтора в слабокислом флюиде.

Следующим по концентрации идет кальций, который в слабощелочных условиях контролируется присутствием в твердофазовой ассоциации кальцита, при этом концентрация Са около $10^{-5} \mathrm{~m}$. В слабокислых условиях вместо кальцита образуется ангидрит, концентрация кальция здесь повышается и составляет примерно $10^{-3} \mathrm{~m}$, повышаясь к $100{ }^{\circ} \mathrm{C}$ до $10^{-2} \mathrm{~m}$, благодаря уменьшающемуся количеству осаждающегося ангидрита при понижении температуры. Самой низкой оказывается концентрация фосфора. В слабощелочном флюиде его кривая опускается до $10^{-7} \mathrm{~m}$, что обусловлено образованием РЗЭ-фторапатита во всем исследованном интервале параметров, а в слабокислых условиях она в высокотемпературной области превышает $10^{-5} \mathrm{~m}$, понижаясь к $200-100{ }^{\circ} \mathrm{C}$ до примерно $10^{-6} \mathrm{~m}$, т. к. при слабокислом флюиде РЗЭ-фторапатит образуется только в интервале $300-100{ }^{\circ} \mathrm{C}$ в возрастающих количествах при понижении температуры [15].

На рис. 2 представлены зависимости концентраций микрокомпонентов системы (Ln+Y) от параметров охлаждающихся флюидов: слабощелочного $\left(1 \mathrm{mNaCl}+5 \mathrm{~m} \mathrm{NaHCO}{ }_{3}+2 \mathrm{~m} \mathrm{Na} \mathrm{Na}_{4}+0,1 \mathrm{~m}\right.$ $\mathrm{HF}+0,1 \mathrm{~m} \mathrm{H}_{2} \mathrm{~S}+1,5 \mathrm{~m} \mathrm{HCl}+(0,401 \mathrm{i}) \mathrm{m} \mathrm{KOH}+1 \mathrm{\kappa \Gamma}$ $\left.\mathrm{H}_{2} \mathrm{O}\right)$ (вверху) и слабокислого $(1 \mathrm{mNaCl}+5 \mathrm{~m}$ $\mathrm{NaHCO}_{3}+2 \mathrm{~m} \mathrm{NaHSO}_{4}+0,1 \mathrm{~m} \mathrm{HF}+0,1 \mathrm{~m} \mathrm{H}_{2} \mathrm{~S}+3,8 \mathrm{~m}$ $\left.\mathrm{HCl}+0,4(\mathrm{i}-0,5) \mathrm{m} \mathrm{KOH}+1 \kappa \Gamma \mathrm{H}_{2} \mathrm{O}\right)$ (внизу). Хорошо видно, что характер поведения лантаноидов и иттрия в разных по кислотности-щелочности условиях заметно различается. В слабощелочном варианте наблюдается монотонное снижение концентраций практически всех микрокомпонентов при понижении температуры от значений $10^{-5}-10^{-9} \mathrm{~m}$ при $500{ }^{\circ} \mathrm{C}$ до $10^{-10}-10^{-13} \mathrm{~m}$ при $100{ }^{\circ} \mathrm{C}$. Это в первую очередь, очевидно, обусловлено устойчивостью РЗЭ-фторапатита во всем интервале параметров, при этом начиная с $300{ }^{\circ} \mathrm{C}$ крутизна кривых кон- центраций несколько увеличивается за счет образования в этой области РЗЭ-флюорита.

При слабокислых условиях кривые концентраций располагаются широкой полосой в основном в области $10^{-6}-10^{-12} \mathrm{~m}$, хотя в области $300-100{ }^{\circ} \mathrm{C}$, где образуются РЗЭ-фторапатит и РЗЭ-флюорит для тяжелых лантаноидов, отмечается падение их концентраций, за исключением иттербия, который, как отмечалось в работе [16], имеет самую низкую мольную долю в РЗЭ-рлюорите, т. е. Үb предпочитает оставаться во флюиде. В обоих вариантах особняком стоит иттрий, у которого оказывается очень устойчивым фторокомплекс, обусловливающий высокие концентрации Y, особенно в высокотемпературной области, где его концентрация контролируется образованием ксенотима и отсутствует его дополнительный осадитель - РЗЭ-флюорит.

На рис. 3 представлено распределение по формам Nd как представителя легких РЗЭ (ЛРЗЭ), Gd - средних РЗЭ (СРЗЭ) и Еr - тяжелых (ТРЗЭ) в зависимости от параметров (подписи к оси абсцисс) охлаждающегося хлоридно-сульфатно-карбонатного слабощелочного флюида с подчиненными концентрациями $\mathrm{H}_{2} \mathrm{~S}$ и $\mathrm{HF}$. Для поддержания определенного близнейтрального слабощелочного $\mathrm{pH}$ флюида в него добавлялись соответствующие концентрации $\mathrm{HCl}$ и $\mathrm{KOH}$. Для всех трех $\mathrm{P} 3 Э$ в высокотемпературной области вплоть до температуры $200{ }^{\circ} \mathrm{C}$ ведущим оказывается нейтральный гидроксокомплекс $\operatorname{Ln}(\mathrm{OH})_{3}{ }^{0}$. Вслед за нейтральным второе место вплоть до температуры $300{ }^{\circ} \mathrm{C}$ занимает второй гидроксокомплекс $\operatorname{Ln}(\mathrm{OH})_{2}{ }^{+}$. Следующим по значимости для представителя ЛРЗЭ Nd оказывается бисульфатный комплекс $\mathrm{Nd}\left(\mathrm{SO}_{4}\right)_{2}{ }^{-}$до температуры $300{ }^{\circ} \mathrm{C}$, после чего он уступает место второму фторокомплексу $\mathrm{NdF}_{2}^{+}$. Следует отметить, что при $200{ }^{\circ} \mathrm{C}$ равнозначными по концентрации оказываются три комплекса: $\mathrm{Nd}(\mathrm{OH})_{2}^{+}, \mathrm{Nd}\left(\mathrm{SO}_{4}\right)_{2}{ }^{-}$и $\mathrm{NdF}_{2}^{+}$(около $10^{-10} \mathrm{~m}$ ). При $100{ }^{\circ} \mathrm{C} \mathrm{NdF}{ }_{2}^{+}$становится ведущим комплексом, к которому присоединяется карбонатный комплекс $\mathrm{NdCO}_{3}^{+}$, за ним следуют $\mathrm{Nd}\left(\mathrm{SO}_{4}\right)_{2}^{-}$и первый фторокомплекс $\mathrm{NdF}^{+2}$. В целом концентрация неодима плавно снижается при понижении температуры (и сопряженных с ней параметров) от $10^{-8}$ при $500{ }^{\circ} \mathrm{C}$ до $10^{-12} \mathrm{~m}$ при $100{ }^{\circ} \mathrm{C}$.

C увеличением атомного номера лантаноида картина меняется: для Gd и $\mathrm{Er}$ после гидроксокомплексов третью позицию в высокотемпературной области занимает второй фторокомплекс $\mathrm{LnF}_{2}{ }^{+}$ вплоть до температуры $200{ }^{\circ} \mathrm{C}$, а при $100{ }^{\circ} \mathrm{C} \mathrm{oн,} \mathrm{как}$ и для неодима, становится ведущим комплексом. Для гадолиния во всем температурном интервале вслед за вторым фторокомплексом параллельно ему следует бисульфатный комплекс $\mathrm{Gd}\left(\mathrm{SO}_{4}\right)_{2}^{-}$, а при $100{ }^{\circ} \mathrm{C}$ за ними следует $\mathrm{GdCO}_{3}{ }^{+}$. Общая концентрация Gd снижается при понижении температуры от 500 к $100^{\circ}$ от $10^{-9,5}$ до $10^{-13} \mathrm{~m}$ соответственно. Для $\mathrm{Er}$ общая концентрация при понижении температуры также плавно снижается, но от $10^{-7}$ до $10^{-11} \mathrm{~m}$, и последовательность концентраций комплексов сохраняется, с той разницей, что начиная 


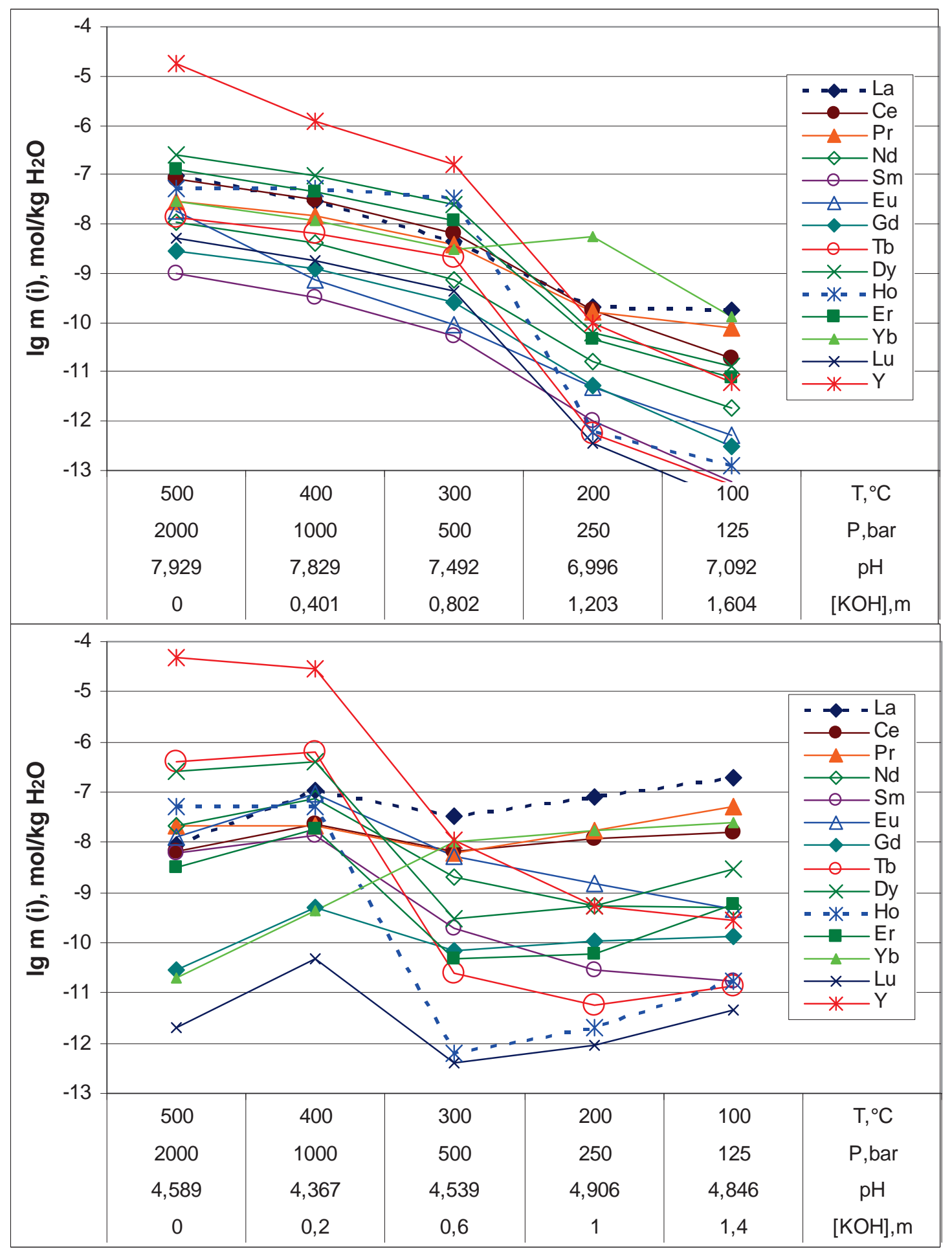

Pис.2. Концентращии $\mathrm{Ln}+Y$ в равновесных слабощелочном (исходные концентращии: $1 \mathrm{mNaCl}+5 \mathrm{~m} \mathrm{NaHCO}+2 \mathrm{~m} \mathrm{Na} \mathrm{NO}_{4}+0,1 \mathrm{~m}$ $\left.\mathrm{HF}+0,1 \mathrm{~m} \mathrm{H}_{2} \mathrm{~S}+1,5 \mathrm{~m} \mathrm{HCl}+(0,401 i) \mathrm{m} \mathrm{KOH+1} \mathrm{\kappa 2} \mathrm{H}_{2} \mathrm{O}\right)$ и слабокислом $(1 \mathrm{mNaCl}+5 \mathrm{~m} \mathrm{NaHCO}+2 \mathrm{~m} \mathrm{NaHSO}+0,1 \mathrm{~m} \mathrm{HF}+0,1 \mathrm{~m}$ $\mathrm{H}_{2} \mathrm{~S}+3,8 \mathrm{~m} \mathrm{HCl+0,4(i-0,5)} \mathrm{m} \mathrm{KOH}+1$ кг $\left.\mathrm{H}_{2} \mathrm{O}\right)$ хлоридно-сульфатно-карбонатных охлаждающихся флюидах, где $i$ - шаг расчета $\left(0-500^{\circ} \mathrm{C}, 2000\right.$ бар; $4-100^{\circ} \mathrm{C}, 125$ бар)

Fig. 2. Concentrations of $\mathrm{Ln}+Y$ in equilibrium cooling weakly alkaline fluid (initial concentrations: $1 \mathrm{~m} \mathrm{NaCl+5} \mathrm{m} \mathrm{NaHCO}_{3}+2 \mathrm{~m}$ $\mathrm{Na}_{2} \mathrm{SO}_{4}+0,1 \mathrm{~m} \mathrm{HF}+0,1 \mathrm{~m} \mathrm{H}_{2} \mathrm{~S}+1,5 \mathrm{~m} \mathrm{HCl}+(0,401 \mathrm{i}) \mathrm{m} \mathrm{KOH}+1 \mathrm{~kg} \mathrm{H}_{2} \mathrm{O}$ ) and in cooling weakly acidic fluid (initial concentrations: $1 \mathrm{mNaCl}+5 \mathrm{~m} \mathrm{NaHCO}_{3}+2 \mathrm{~m} \mathrm{NaHSO}_{4}+0,1 \mathrm{~m} \mathrm{HF}^{2}, 1 \mathrm{~m} \mathrm{H}_{2} \mathrm{~S}+3,8 \mathrm{~m} \mathrm{HCl}+0,4(i-0,5) \mathrm{m} \mathrm{KOH}+1 \mathrm{~kg} \mathrm{H} \mathrm{H}_{2}$. Where $i$ is the calculation step $(0$ $-500^{\circ} \mathrm{C}, 2000$ bar; $\left.4-100^{\circ} \mathrm{C}, 125 \mathrm{bar}\right)$ 


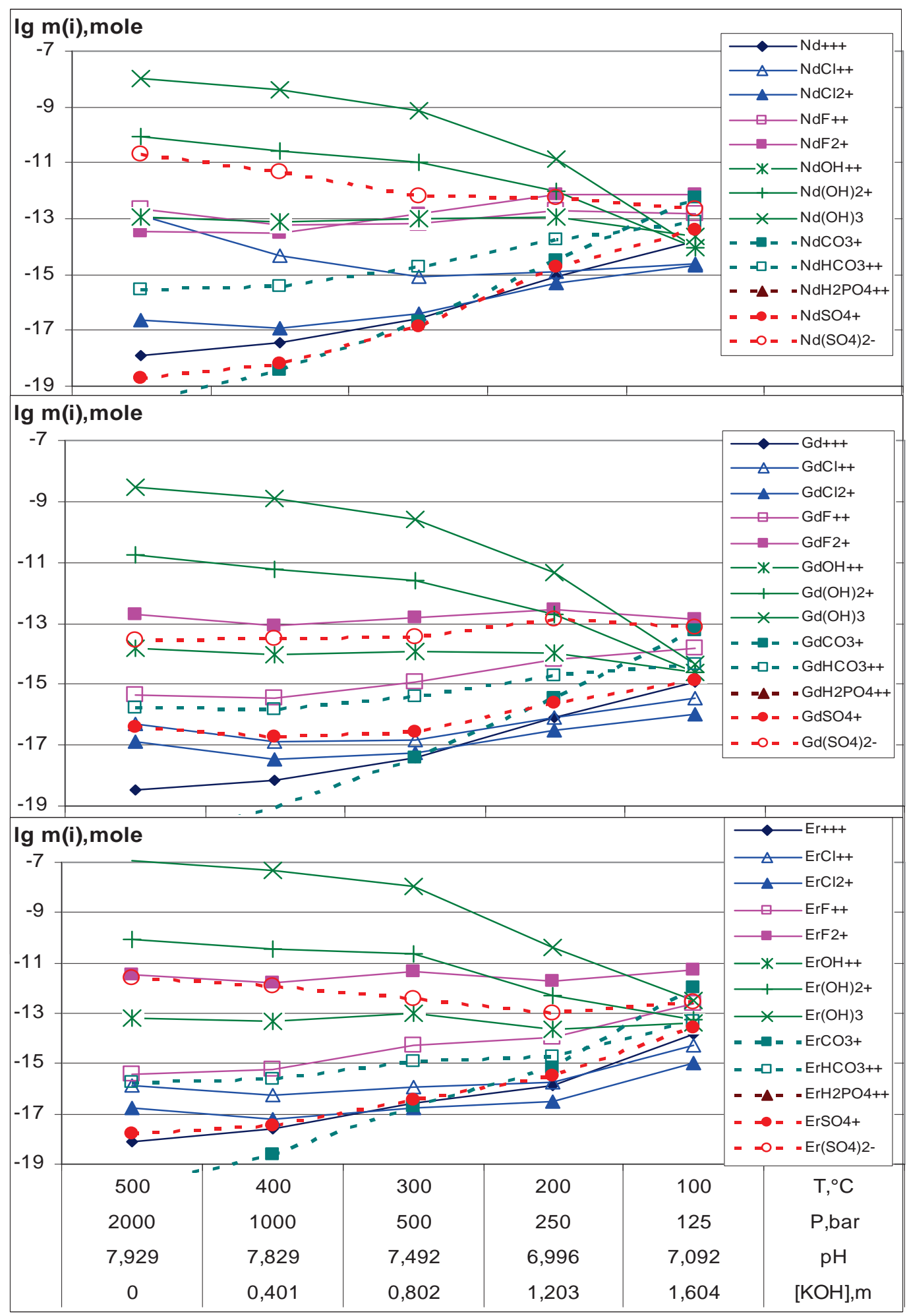

Puс. 3. Распределение по формам $\mathrm{Nd}, \mathrm{Gd}$ и Er в слабощелочном охлаждающемся флюиде: $\left[0,12 \text {-моль } \mathrm{CaCO}_{3}+0,0053 \text { 2-моль монацита }\right]_{\text {тв. }}$ $+1 \mathrm{mNaCl}+5 \mathrm{~m} \mathrm{NaHCO}_{3}+2 \mathrm{~m} \mathrm{Na}_{2} \mathrm{SO}_{4}+0,1 \mathrm{~m} \mathrm{HF}^{2}, 1 \mathrm{~m} \mathrm{H}_{2} \mathrm{~S}+1,5 \mathrm{~m} \mathrm{HCl+}(0,401 i) \mathrm{m} \mathrm{KOH}+1 \kappa$ г $\mathrm{H}_{2} \mathrm{O}$, где i - шаг расчета $\left(0-500^{\circ} \mathrm{C}\right.$, 2000 бар; $4-100^{\circ} \mathrm{C}, 125$ бар)

Fig. 3. Speciation of $\mathrm{Nd}, \mathrm{Gd}$ and Er in cooling weakly alkaline ore-forming fluid: $\left[0,1 \text { mole } \mathrm{CaCO}_{3}+0,0053 \text { mole monazite }\right]_{\text {solid }}+1 \mathrm{mNaCl}+5 \mathrm{~m}$ $\mathrm{NaHCO}_{3}+2 \mathrm{~m} \mathrm{Na}_{2} \mathrm{SO}_{4}+0,1 \mathrm{~m} \mathrm{HF}+0,1 \mathrm{~m} \mathrm{H}_{2} \mathrm{~S}+1,5 \mathrm{~m} \mathrm{HCl}+(0,401 \mathrm{i}) \mathrm{m} \mathrm{KOH}+1 \mathrm{~kg} \mathrm{H} \mathrm{H}_{2} \mathrm{O}$. Where $i$ is the calculation step $\left(0-500^{\circ} \mathrm{C}\right.$, 2000 bar; $4-100^{\circ} \mathrm{C}, 125$ bar) 

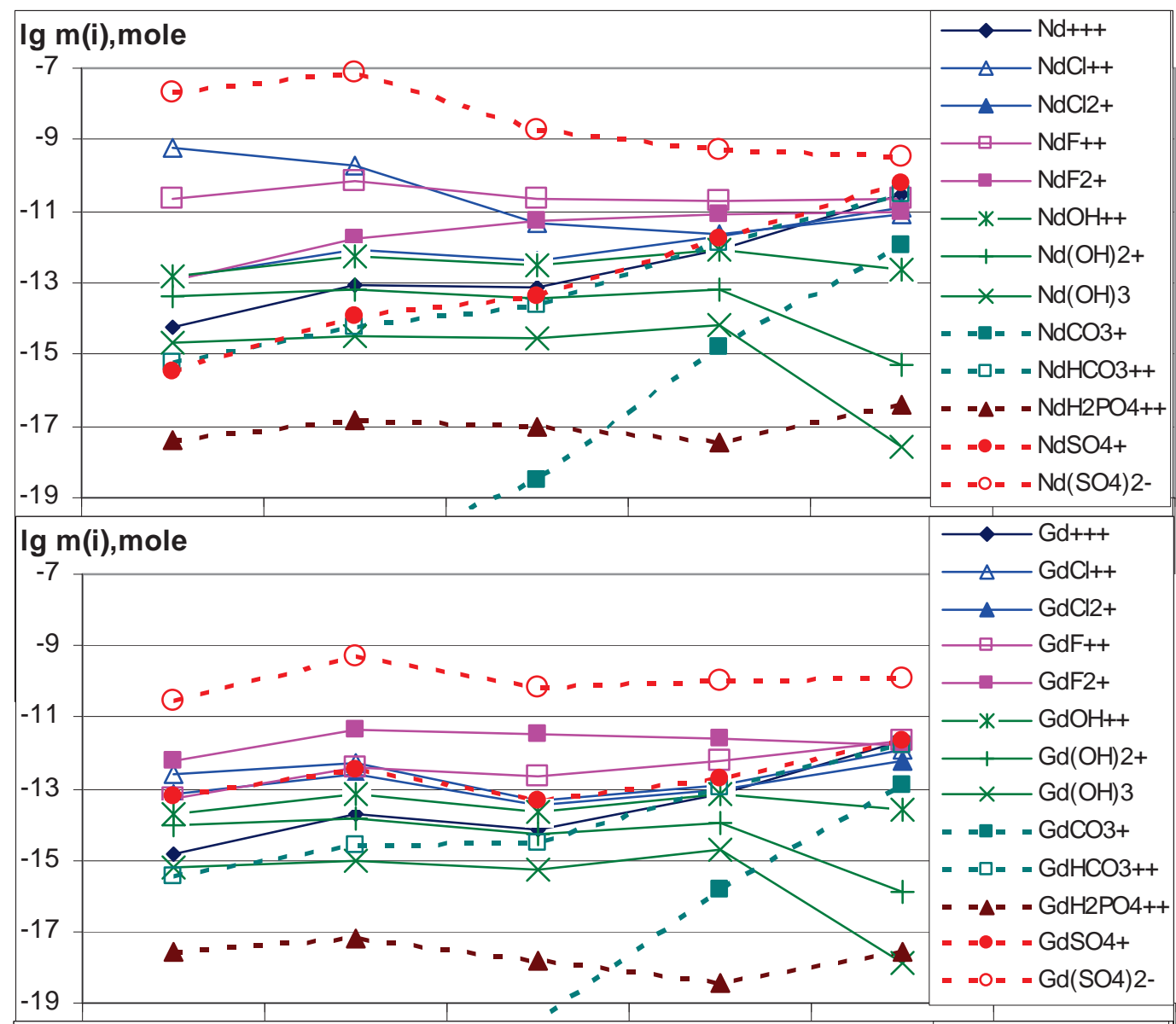

$\longrightarrow-\mathrm{Gd+++}$

$\triangle \mathrm{GdCl}++$

$\longrightarrow-\mathrm{GdCl} 2+$

$\square-\mathrm{GdF}++$

$\longrightarrow-\mathrm{GdF} 2+$

- $*-\mathrm{GdOH}++$

$1-\mathrm{Gd}(\mathrm{OH}) 2+$

$\times \quad \mathrm{Gd}(\mathrm{OH}) 3$

- - - - GdCO3+

$-\square-$ - GdHCO3++

- - - - GdH2PO4++

-๑- - GdSO4+

$-0--\mathrm{Gd}(\mathrm{SO} 4) 2-$

\section{$\lg \mathrm{m}(\mathrm{i})$, mole}

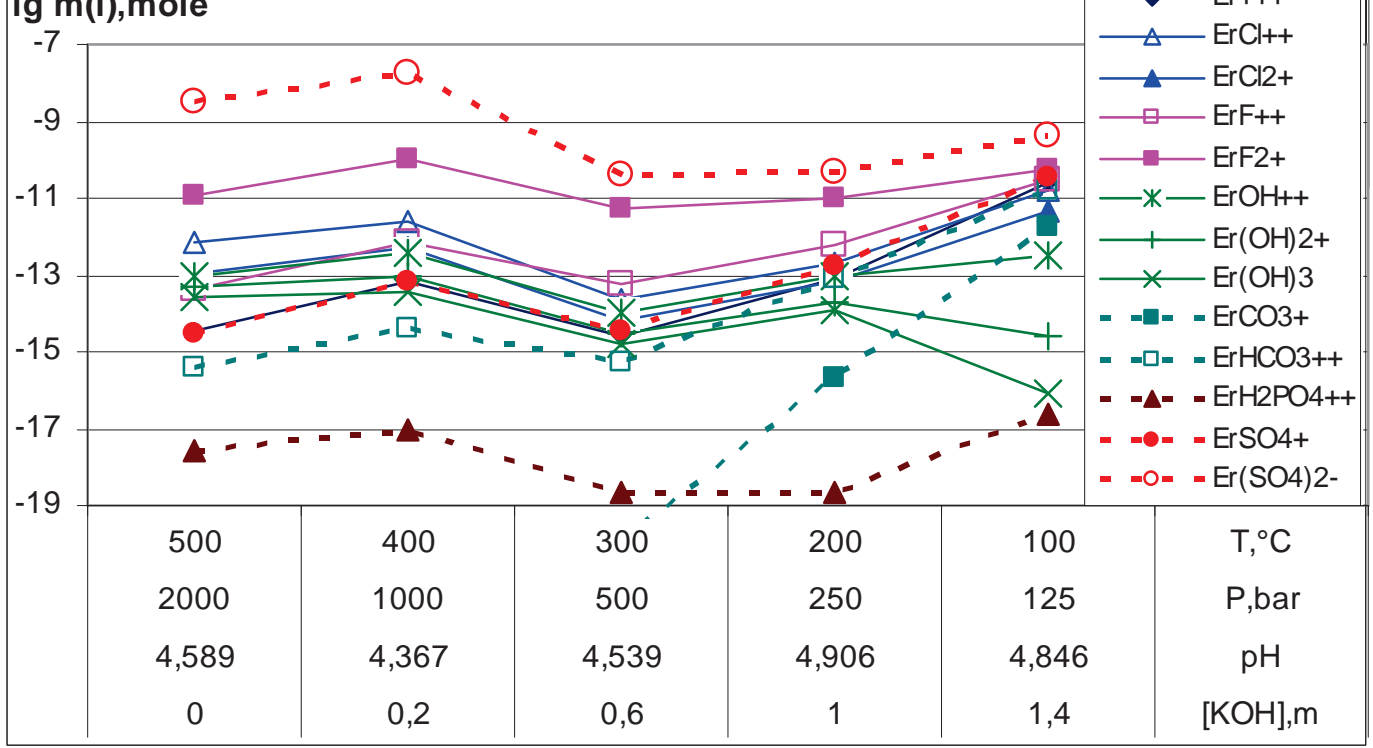

Puc.4. Распределение по формам $\mathrm{Nd}$, Gd и Er в слабокислом охлаждающемся флюиде: $\left[0,12 \text {-моль } \mathrm{CaCO}_{3}+0,0053 \text { 2-моль монацита }\right]_{\text {тв. }}$

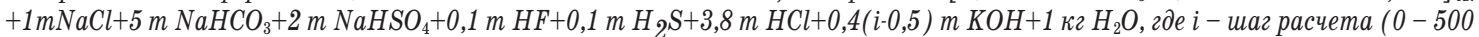
${ }^{\circ} \mathrm{C}, 2000$ бар; $4-100^{\circ} \mathrm{C}, 125$ бар)

Fig. 4. Speciation of $\mathrm{Nd}, \mathrm{Gd}$ and $\mathrm{Er}$ in cooling weakly acidic ore-forming fluid: $\left[0,1 \text { mole } \mathrm{CaCO}_{3}+0,0053 \text { mole monazite }\right]_{\text {solid }}+1 \mathrm{mNaCl}+5 \mathrm{~m}$ $\mathrm{NaHCO}_{3}+2 \mathrm{~m} \mathrm{NaHSO}_{4}+0,1 \mathrm{~m} \mathrm{HF}^{2} 0,1 \mathrm{~m} \mathrm{H}_{2} \mathrm{~S}+3,8 \mathrm{~m} \mathrm{HCl}+0,4(\mathrm{i}-0,5) \mathrm{m} \mathrm{KOH}+1 \mathrm{~kg} \mathrm{H}_{2} \mathrm{O}$. Where $i$ is the calculation step $\left(0-500^{\circ} \mathrm{C}\right.$, 2000 bar; $4-100^{\circ} \mathrm{C}, 125$ bar) 
с температуры $300{ }^{\circ} \mathrm{C}$ и ниже усиливается роль второго фторокомплекса эрбия и заметно падает концентрация бисульфатного комплекса $\operatorname{Er}\left(\mathrm{SO}_{4}\right)_{2}{ }^{-}$, так что при $100{ }^{\circ} \mathrm{C}$ он уже уступает место и карбонатному комплексу $\mathrm{ErCO}_{3}^{+}$. В целом для слабощелочного варианта с увеличением атомного номера лантаноида наблюдается усиление устойчивости второго фторокомплекса, особенно при понижении температуры и ослабление бисульфатного комплекса. Хлоридные комплексы в слабощелочном варианте не играют существенной роли и совсем не делают вклада фосфатные комплексы (не умещаются на шкале концентраций, т. е. их концентрация ниже $\left.10^{-19} \mathrm{~m}\right)$.

На рис. 4 показано распределение этих же лантаноидов $(\mathrm{Nd}, \mathrm{Gd}$ и $\mathrm{Tb})$ для слабокислого флюида. Для всех трех лантаноидов ведущим оказывается бисульфатный комплекс $\operatorname{Ln}\left(\mathrm{SO}_{4}\right)_{2}^{-}$, на один-два порядка превышающий концентрации остальных комплексов. Для представителя ЛРЗЭ $\mathrm{Nd}$ в высокотемпературной области $\left(500-400{ }^{\circ} \mathrm{C}\right)$ второе место занимает его первый хлорокомплекс $\mathrm{NdCl}^{+2}$, который, как и другие хлорокомплексы, для СРЗЭ и ТРЗЭ не играет существенной роли. Следующим важным для транспорта неодима оказывается первый фторокомплекс $\mathrm{NdF}^{+2}$, который начиная с $300{ }^{\circ} \mathrm{C}$ выходит на второе место по значимости, вслед за ним идет второй фторокомплекс $\mathrm{LnF}_{2}{ }^{+}$, но при $100{ }^{\circ} \mathrm{C}$ оба они уступают место сульфатному комплексу $\mathrm{NdSO}_{4}^{+}$, а вслед за ним и гидрокарбонатному $-\mathrm{NdHCO}_{3}^{+2}$.

С увеличением атомного номера лантаноида на второе место после бисульратного комплекса Ln $\left(\mathrm{SO}_{4}\right)_{2}^{-}$выходит второй фторокомплекс $\mathrm{LnF}_{2}^{+}$как для гадолиния, так и для эрбия, причем для последнего он значительно преобладает над остальными частицами флюида. При $100{ }^{\circ} \mathrm{C}$ в обоих случаях $\kappa$ нему присоединяются первый фтторокомплекс $\mathrm{LnF}^{+2}$, сульфатный комплекс $\mathrm{NdSO}_{4}^{+}$и гидрокарбонатный $\mathrm{NdHCO}_{3}^{+2}$. Интересно, что в слабокислом флюиде повышается концентрация фосфатного комплекса, причем для неодима его концентрация колеблется около $10^{-17} \mathrm{~m}$, а для гадолиния и эрбия колеблется между $10^{-17}-10^{-19} \mathrm{~m}$. В целом снова, как и для слабощелочного варианта, в слабокислом флюиде с увеличением номера лантаноида наблюдается усиление устойчивости их второго фторокомплекса $\mathrm{LnF}_{2}{ }^{+}$. Отличительной чертой для слабокислого варианта является появление значимой концентрации первого хлорокомплекса для ЛРЗЭ при 500-400 ${ }^{\circ} \mathrm{C}$ (который является даже ведущим для $\mathrm{Ce}$ и $\operatorname{Pr}$ при $\left.500{ }^{\circ} \mathrm{C}\right)$, и гидрокарбонатного - при $100{ }^{\circ} \mathrm{C}$ для всех лантаноидов наряду с сульфатным комплексом $\mathrm{LnSO}_{4}^{+}$.

Появившиеся термодинамические данные для фторокарбонатов РЗЭ бастнезита $\left(\mathrm{Ce}_{0,5} \mathrm{La}_{0,25} \mathrm{Nd}_{0,2} \mathrm{Pr}_{0,05} \mathrm{CO}_{3} \mathrm{~F}\right)$ и паризита $\left(\mathrm{CaCe}_{0,95} \mathrm{La}_{0,6} \mathrm{Nd}_{0,35} \mathrm{Pr}_{0,1}\left(\mathrm{CO}_{3}\right)_{3} \mathrm{~F}_{2}\right)$ при повышенных температурах [21], как для минералов постоянного состава, позволили провести термодинамические расчеты с учетом возможности их присутствия в равновесных ассоциациях. Наличие эт- их минералов в минеральных ассоциациях таких месторождений, как уникальное карбонатитовое Баян Обо [1] и Олимпик Дам [22], делает актуальной оценку их влияния на распределение других РЗЭ-содержащих минералов и состав равновесного гидротермального флюида в близнейтральных условиях.

На рис. 5 приведено соотношение равновесных твердых фаз в варианте слабощелочного охлаждающегося гидротермального флюида в случае учета возможности образования бастнезита и паризита. Их присутствие наблюдается во всем исследованном интервале параметров флюида (бастнезит присутствует в подчиненном количестве $-1,1 \cdot 10^{-3}$, а

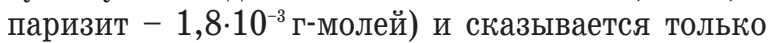
на перераспределении РЗЭ-содержащих минералов, практически не затрагивая равновесной ассоциации макросистемы (ср. с аналогичным рис. 1 [16]). В частности, резко уменьшается количество равновесного монацита (в пределах от $3 \cdot 10^{-5}$ при $500{ }^{\circ} \mathrm{C}$ до $5 \cdot 10^{-4}$ при $300{ }^{\circ} \mathrm{C}$ и $1,5 \cdot 10^{-4}$ г-моля при $\left.100{ }^{\circ} \mathrm{C}\right)$, возрастает количество РЗЭ-фторапатита (около $1,5 \cdot 10^{-3} \Gamma$-моля), причем он как бы является антагонистом монацита, кривая содержания которого носит выпуклый характер, а РЗЭ-фторапатита вогнутый. Ксенотим оказывается устойчивым только при 400 и $300{ }^{\circ} \mathrm{C}\left(2 \cdot 10^{-5}\right.$ и $2,5 \cdot 10^{-4}$ г-моля соответственно), а РЗЭ флюорит в значимых количествах - при 200 и $100{ }^{\circ} \mathrm{C}\left(1,4 \cdot 10^{-2}\right.$ и $2,7 \cdot 10^{-2}$ г-моля соответственно).

На рис. 6 для варианта возможного образования бастнезита и паризита представлены концентрации макро- и микрокомпонентов системы и распределение по формам Gd в слабощелочном охлаждающемся флюиде, равновесные минеральные ассоциации которого приведены на рис. 5. Что касается макрокомпонентов системы (S, F, Ca и P), то они практически совпадают с их концентрациями при расчетах при отсутствии бастнезита и паризита (рис. 1). Для микрокомпонентов системы ситуация меняется: в сравнении с рис. 2 (верхняя часть) кривые концентраций лантаноидов и иттрия хотя и также монотонно падают с понижением температуры, но располагаются боле узкой полосой. Так, в данном случае при $500{ }^{\circ} \mathrm{C}$ они располагаются от $10^{-3,6}$ до $10^{-6,7}$, тогда как при отсутствии бастнезита и паризита - от $10^{-5}$ до $10^{-9} \mathrm{~m}$; при $200{ }^{\circ} \mathrm{C}$ в присутствии фторокарбонатов от $10^{-6,9}$ до $10^{-10,5}$ при их отсутствии примерно от $10^{-8}$ до $10^{-12,5} \mathrm{~m}$. Кроме того, образование бастнезита и паризита приводит к резкому уменьшению концентраций $\mathrm{La}$ и $\mathrm{Nd}$ $\left(<10^{-14} \mathrm{~m}\right)$, входящих в значимых количествах в состав этих минералов, так что кривые их концентраций во флюиде не отражаются на рис. 6 .

В нижней части рис. 6 для примера показано распределение по формам Gd в слабощелочном флюиде в случае учета образования бастнезита и паризита. В интервале температур 500-200 ${ }^{\circ} \mathrm{C}$ последовательность значимости комплексов гадолиния совпадает с таковой для варианта без учета образования фторокарбонатов $\mathrm{P} 3 Э: \mathrm{Gd}(\mathrm{OH})_{3}{ }^{0}>\mathrm{Gd}(\mathrm{OH})_{2}{ }^{+}>\mathrm{GdF}_{2}{ }^{+}>\mathrm{Gd}\left(\mathrm{SO}_{4}\right)_{2}{ }^{-}$. 


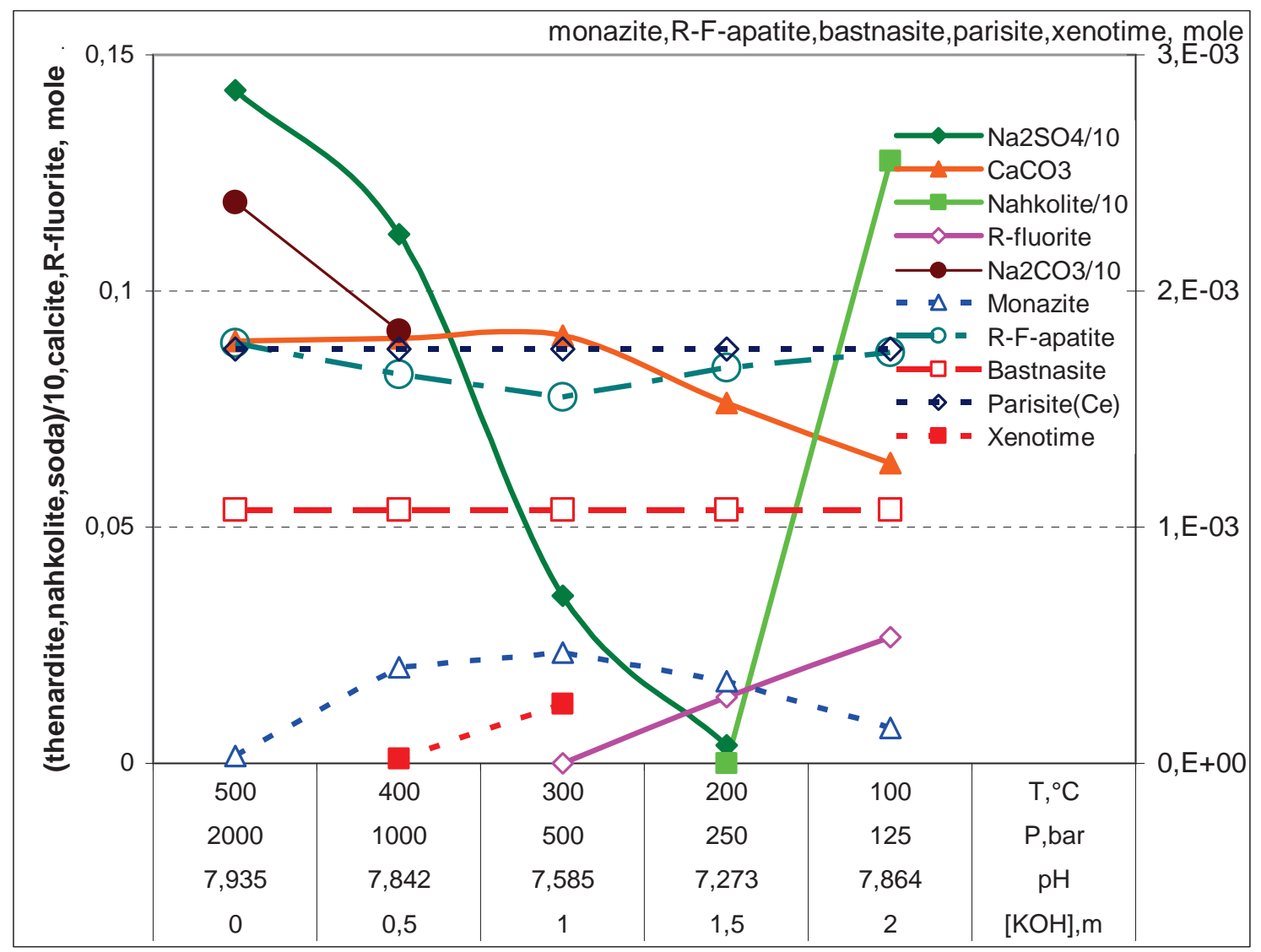

Pис. 5. Соотношение равновесных твердых фаз в варианте в случае учета возложности образования бастнезита и паризита в зависимости от параметров охлаждающегося слабощелочного гидротерлального флюида (подписи к шкале абсиисс). Сплошные линии относятся к левой шкале ординат, пунктирные - к правой шкале. Исходный состав систелы: $[0,1$ г-моль СаСО $3+0,0053$ г-

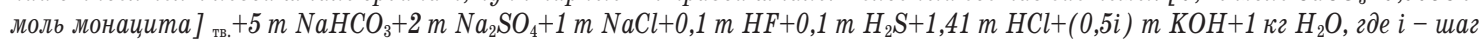
расчета $\left(0-500^{\circ} \mathrm{C}, 2000\right.$ бар; $4-100^{\circ} \mathrm{C}, 125$ бар)

Fig. 5. Equilibrium solid phase relationships as a function of the parameters of a cooling weakly alkaline hydrothermal fluid. Initial system

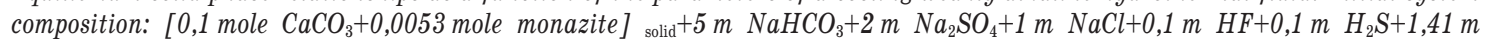
$\mathrm{HCl}+(0,5 \mathrm{i}) \mathrm{m} \mathrm{KOH}+1 \mathrm{~kg} \mathrm{H}_{2} \mathrm{O}$. Where $i$ is the calculation step $\left(0-500^{\circ} \mathrm{C}, 2000 \mathrm{bar} ; 4-100^{\circ} \mathrm{C}, 125 \mathrm{bar}\right)$

Остальные комплексы не вносят значимого вклада: их концентрации в обоих случаях ниже уровня $10^{-13} \mathrm{~m}$. При $100{ }^{\circ} \mathrm{C}$ в варианте с учетом образования бастнезита и паризита $\mathrm{pH}$ раствора получился выше $(7,86$ вместо 7,09$)$, что привело к усилению роли нейтрального гидроксокомплекса $\mathrm{Gd}(\mathrm{OH})_{3}{ }^{0}$, концентрация которого здесь почти сравнялась с концентрацией второго фторокомплекса $\mathrm{GdF}_{2}^{+}$, и немного возросла роль карбонатного комплекса $\mathrm{GdCO}_{3}^{+}$. На этом примере хорошо видно, что $\mathrm{pH}$ играет важную роль в распределении РЗЭ по формам во флюиде.

\section{Заключение}

Изучение распределения РЗЭ+Ү по формам во флюидах показало, что оно большей частью зависит от кислотно-щелочной обстановки минералообразования, а также от температуры и сопряженных с нею параметров. Немаловажное значение имеет увеличение номера лантаноида: для тяжелых РЗЭ усиливается роль фторидных комплексов и ослабляется вклад сульфатных комплексов. При повы- шенных T-Р параметрах в слабощелочных флюидах главными транспортирующими являются гидроксокомплексы, тогда как в слабокислых условиях во всем диапазоне параметров резко преобладают сульфатные комплексы. При охлаждении равновесного флюида от 500 до $100{ }^{\circ} \mathrm{C}$ общая концентрация РЗЭ+Y в слабощелочных флюидах понижается монотонно от примерно $10^{-5}$ до $10^{-10} \mathrm{~m}$, тогда как в слабокислых условиях их общая концентрация снижается от $10^{-4}$ до $10^{-7} \mathrm{~m}$. При $100{ }^{\circ} \mathrm{C}$ в слабощелочных условиях РЗЭ+Ү преимущественно находятся в виде второго фторокомплекса $\left(\mathrm{Ln}, \mathrm{Y}_{2} \mathrm{~F}_{2}^{+}\right.$. Установлено, что карбонат-бикарбонатные комплексы делают некоторый вклад только при $100{ }^{\circ} \mathrm{C}$, а фосфатные комплексы вообще не имеют значения при транспорте РЗЭ+Y во всем исследованном интервале параметров благодаря низкой растворимости монацита, ксенотима и РЗЭ-фторапатита. К ограничениям модели относятся: 1) для повышенных температур термодинамические данные водных гидроксокомплексов РЗЭ, а также бикарбоната, карбоната и фосфата получены на основании экстраполяции из экс- 


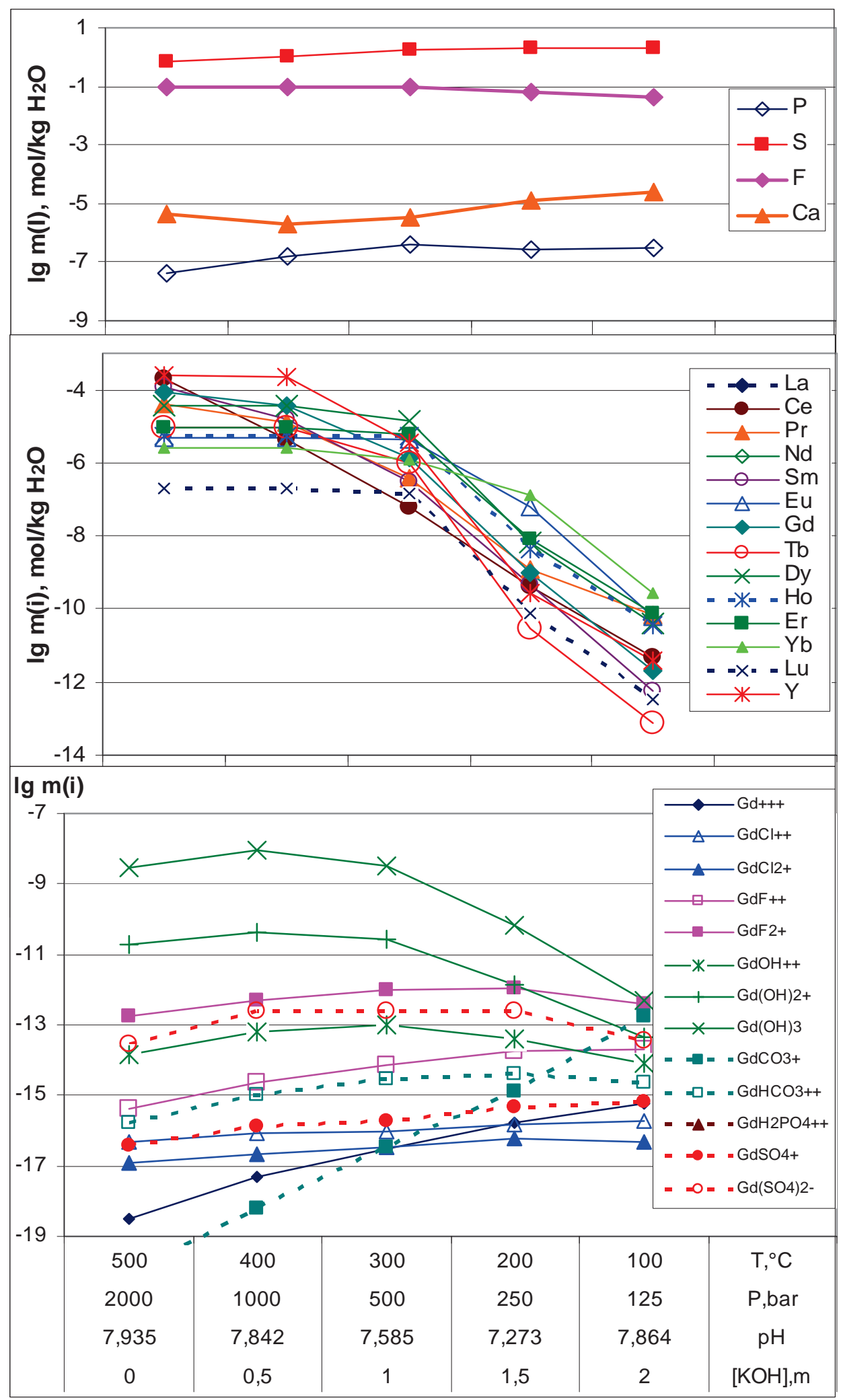

Puc. 6. Концентрации макро- и микрокомпонентов системы и распределение по формам Gd в слабощелочном охлаждающемся флюиде в варианте возможного образования бастнезита и паризита (см. рис. 5)

Fig. 6. Concentrations of macro- and micro-components of the system and speciation of Gd in a weakly alkaline cooling fluid in the variant of possible formation of bastnasite and parizite (see Fig. 5) 
периментов при температуре окружающей среды [17]; 2) использованы данные для фторокарбонатов РЗЭ бастнезита $\left(\mathrm{Ce}_{0,5} \mathrm{La}_{0,25} \mathrm{Nd}_{0,2} \mathrm{Pr}_{0,05} \mathrm{CO}_{3} \mathrm{~F}\right)$ и паризита $\left(\mathrm{CaCe}_{0,95} \mathrm{La}_{0,6} \mathrm{Nd}_{0,35} \mathrm{Pr}_{0,1}\left(\mathrm{CO}_{3}\right)_{3} \mathrm{~F}_{2}\right)$ при повышенных температурах как для минералов постоянного состава [21], хотя для бастнезита из месторождения Олимпик Дам в [22] приведена другая формула этого минерала - $\left(\mathrm{Ca}, \mathrm{Sr}_{0,01} \mathrm{La}_{0,31} \mathrm{Ce}_{0,49} \mathrm{Nd}_{0,12}(\mathrm{M}-\mathrm{HREE})_{0,08}\right)_{1} \mathrm{~F}_{0,75} \mathrm{CO}_{3}$

\section{СПИСОК ЛИТЕРАТУРЫ}

1. Smith M.P., Henderson P., Campbell L.S. Fractionation of the REE during hydrothermal processes: Constraints from the Bayan Obo Fe-REE-Nb deposit, Inner Mongolia, China // Geochimica et Cosmochimica Acta. - 2000. - V. 64. - № 18. - P. 3141-3160.

2. Gysi A.P., Williams-Jones A.E., Collins P. Lithogeochemical vectors for hydrothermal processes in the Strange Lake peralkaline granitic REE-Zr-Nb deposit // Economic Geology. - 2016. V. 111. - № 5. - P. 1241-1276.

3. Moller V., Williams-Jones A.E. Petrogenesis of the Nechalacho Layered Suite, Canada: Magmatic Evolution of a REE-NbrichNepheline Syenite Intrusion // Journal of Petrology. 2016. - V. 57. - № 2. - P. 229-276.

4. Castor S.B. The Mountain Pass rare-earth carbonatite and associated ultrapotassic rocks, California // The Canadian Mineralogist. - 2008. - V. 46. - № 4. - P. 779-806.

5. REE fractionation, mineral speciation, and supergene enrichment of the Bear Lodge carbonatites, Wyoming / A.K. Andersen, J.G. Clark, P.B. Larson, J.J. Donovan // Ore Geology Reviews. - 2017. - V. 89. - P. 780-807.

6. Salvi S., Williams-Jones A.E. The role of hydrothermal processes in the granite-hosted Zr, Y, REE deposit at Strange Lake, Quebec/Labrador: Evidence from fluid inclusions // Geochimica et Cosmochimica Acta. - 1990. - V. 54. - № 9. - P. 2403-2418.

7. Gysi A.P., Williams-Jones A.E. Hydrothermal mobilization of pegmatite-hosted REE and Zr at Strange Lake, Canada: a reaction pathmodel // Geochimica et Cosmochimica Acta. -2013. V. 122 . - P. 324-352.

8. Tracing the fluid source of heavy REE mineralisation in carbonatites using a novel method of oxygen-isotope analysis in apatite: the example of Songwe Hill, Malawi / S. Broom-Fendley, T. Heaton, F. Wall, G. Gunn // Chemical Geology. - 2016. - V. 440. - P. 275-287.

9. Migdisov A.A., Williams-Jones A.E. A spectrophotometric study of Nd (III), Sm (III) and Er (III) complexation in sulfate-bearing solutions at elevated temperatures // Geochim. Cosmochim. Acta. 2008. - V. 72. - P. 5291-5303.

10. Migdisov A.A., Williams-Jones A.E., Wagner T. An experimental study of the solubility and speciation of the Rare Earth Elements (III) in fluoride- and chloride-bearing aqueous solutions at temperatures up to $300{ }^{\circ} \mathrm{C} / /$ Geochim. Cosmochim. Acta. 2009. - V. 73. - P. 7087-7109.

11. Migdisov A.A., Williams-Jones A.E. Hydrothermal transport and deposition of the Rare Earth Elements by fluorine-bearing aqueous liquids // Mineral Deposits. - 2014. - V. 49. - P. 987-997.

12. Hydrothermal transport, deposition, and fractionation of the REE: experimental data and thermodynamic calculations / A. Migdisov, и для корректного моделирования требуются дополнительные знания относительно фторокарбонатов РЗЭ для введения их в модель хотя бы в форме идеальных твердых растворов.

Работа выполнена по государственному заданию ИГМ СО РАН (0330-2016-0002). Терлодинамическое моделирование в щелочных системах проведено за счет средств гранта Президента РФ МК-1113.2019.5.

A.E. Williams-Jones, J. Brugger, F.A. Caporuscio // Chemical Geology. - 2016. - V. 439. - P. 13-42.

13. Gysi A.P., Williams-Jones A.E., Harlov D. The solubility of xenotime-(Y) and other HREE phosphates $\left(\mathrm{DyPO}_{4}, \mathrm{ErPO}_{4}\right.$ and $\left.\mathrm{YbPO}_{4}\right)$ in aqueous solutions from 100 to $250{ }^{\circ} \mathrm{C}$ and $\mathrm{p}_{\text {sat }} / /$ Chemical Geology. - 2015. - V. 401. - P. 83-95.

14. Perry E.P., Gysi A.P. Speciation in Hydrothermal Fluids and Partitioning in Calcite // Geofluids. - 2018. - V. 2018. - № 8. P. 1-19.

15. Широносова Г.П., Прокопьев И.Р. Поведение РЗЭ+Ү во фторидно-хлоридно-сульфидно-сульфатно-карбонатных средах на гидротермальных стадиях щелочных магматических комплексов по данным термодинамического моделирования // Известия Томского политехнического университета. Инжиниринг георесурсов. - 2017. - Т. 328. - № 12. - С. 75-83.

16. Широносова Г.П., Прокопьев И.Р. Коэффициенты распределения РЗЭ+Ү между минералами и охлаждающимся богатым сульфатной серой флюидом (термодинамическое моделирование) // Известия Томского политехнического университета. Инжиниринг георесурсов. - 2018. - Т. 329. - № 10. - С. 6-18.

17. Haas J.R., Shock E.L., Sassani D.C. Rare earth elements in hydrothermal systems: Estimates of standard partial molal thermodynamic properties of aqueous complexes of the rare earth elements at high pressures and temperatures // Geochim. Cosmochim. Acta. - 1995. - V. 59. - P. 4329-4350.

18. Экспериментальное изучение гидролитических равновесий в близнейтральных и щелочных растворах редкоземельных элементов при $25{ }^{\circ} \mathrm{C} /$ С.А. Степанчикова, Р.П. Битейкина, Г.П. Широносова, Г.Р. Колонин // Геология и геофизика. 2014. - T. 55. - № 8. - C. 1188-1193.

19. Шваров Ю.В. НCh: новые возможности термодинамического моделирования геохимических процессов, предоставляемые Windows // Геохимия. - 2008. - № 8. - С. 898-903.

20. Shvarov Yu.V., Bastrakov E. HCh: a software package for geochemical equilibrium modeling: User's Guide (AGSO RECORD 1999/y). - Canberra: Australian Geological Survey Organisation, Dept. of Industry, Science and Resources, 1999. - 57 p.

21. Gysi A.P., Williams-Jones A.E. The thermodynamic properties of bastnasite-(Ce) and parisite-(Ce) // Chemical Geology. - 2015. V. 392. - P. 87-101.

22. Rare earth element fluorocarbonate minerals from the Olympic Dam Cu-U-Au-Ag deposit, South Australia / D.S. Schmandt, N.J. Cook, C.L. Ciobanu, K. Ehrig, B.P. Wade, S. Gilbert, V.S. Kamenetsky // Minerals. - 2017. - V. 7, - P. 202.

Поступила 16.10.2018 г.

\section{Информация об авторах}

Широносова Г.П., кандидат геолого-минералогических наук, старший научный сотрудник лаборатории щелочного магматизма и рудообразования Института геологии и минералогии им. В.С. Соболева Сибирского отделения Российской Академии наук.

Прокопьев И.Р., кандидат геолого-минералогических наук, старший научный сотрудник лаборатории щелочного магматизма и рудообразования Института геологии и минералогии им. В.С. Соболева Сибирского отделения Российской Академии наук; старший преподаватель кафедры петрографии и геологии рудных месторождений Геолого-геофизического факультета Новосибирского государственного университета. 
UDC 550.41

THERMODYNAMIC MODELING OF REE+Y SPECIATION IN COOLING SULFATE-RICH FLUIDS

\author{
Galina P. Shironosova', \\ shiron@igm.nsc.ru \\ Ilya R. Prokopyev ${ }^{1,2}$, \\ prokop@igm.nsc.ru \\ 1 V.S. Sobolev Institute of Geology and Mineralogy SB RAS, \\ 3, academician Koptyug avenue, Novosibirsk, 630090, Russia \\ ${ }^{2}$ Novosibirsk State University, \\ 1, Pirogov street, Novosibirsk, 630090, Russia.
}

The relevance of the work is caused by the fact that the study of speciation of lanthanide + yttrium $(R E E+Y)$ in chloride-sulfate-carbonate fluids in various weakly alkaline and weakly acidic conditions allows one to assess the effect of parameters of the ore-forming system on transportation and fractionation of rare-earth elements in oreogenesis within the carbonatite ore-magmatic systems.

The main aim of the study is to estimate the contribution of the fluorine-, chloro-, carbarnate-bicarbonate, sulfate and phosphate complexes of REE $+Y$ to transport and ore deposition by hydrothermal fluids in weakly alkaline and weakly acidic conditions at $500-100{ }^{\circ} \mathrm{C}$ and a pressure of 2000-125 bar.

The methods: computational modeling of the effect of hydrothermal fluids on monazite and calcite using the HCh package (developed by Yu.V. Shvarov). To establish the equilibrium state in the program's algorithm, the method of determining the minimum Gibbs free energy of the system (the GIBBS program) in combination with the thermodynamic base UNITHERM, supplemented by experimental results for REE complexes and minerals, was used.

The results. The paper introduces the distribution of REE $+Y$ by forms in cooling chloride-sulfate-carbonate highly concentrated weakly acidic and weakly alkaline fluids. It was shown that under weakly alkaline conditions, the leading ones are the neutral and second hydrocomplexes up to $200^{\circ} \mathrm{C}$. As the temperature decreases to $100^{\circ} \mathrm{C}, R E E+Y$ are found in the form of the carbonate and second fluorocomplex $(\mathrm{Ln}, Y) \mathrm{F}_{2}{ }^{+}$. Under weakly acidic conditions, sulfate complexes of lanthanides prevail sharply in the entire studied range of fluid parameters. With an increase in the lanthanide number (especially for heavy REEs), the role of fluoride complexes grows with a decrease in contribution of sulfate complexes.

\title{
Keywords:
}

$R E E+Y$, hydroxy-, fluoro-, chloro-, sulfate, phosphate complexes, speciation in the fluid, sulfate-rich fluid, thermodynamic modeling.

This work was carried out according to the state assignment of the IGM SB RAS (0330-2016-0002). Thermodynamic modeling in alkaline systems was carried out at the expense of the grant of the President of the Russian Federation MK-1113.2019.5.

\section{REFERENCES}

1. Smith M.P., Henderson P., Campbell L.S. Fractionation of the REE during hydrothermal processes: Constraints from the Bayan Obo Fe-REE-Nb deposit, Inner Mongolia, China. Geochimica et Cosmochimica Acta, 2000, vol. 64, no. 18, pp. 3141-3160.

2. Gysi A.P., Williams-Jones A.E., Collins P Lithogeochemical vectors for hydrothermal processes in the Strange Lake peralkaline granitic REE-Zr-Nb deposit. Economic Geology, 2016, vol. 111, no. 5, pp. 1241-1276.

3. Moller V., Williams-Jones A.E. Petrogenesis of the Nechalacho Layered Suite, Canada: Magmatic Evolution of a REE-NbrichNepheline Syenite Intrusion. Journal of Petrology, 2016, vol. 57, no. 2, pp. 229-276.

4. Castor S.B. The Mountain Pass rare-earth carbonatite and associated ultrapotassic rocks, California. The Canadian Mineralogist, 2008, vol. 46, no. 4, pp. 779-806.

5. Andersen A.K., Clark J.G., Larson P.B., Donovan J.J. REE fractionation, mineral speciation, and supergene enrichment of the Bear Lodge carbonatites, Wyoming. Ore Geology Reviews, 2017, vol. 89, pp. 780-807.

6. Salvi S., Williams-Jones A.E. The role of hydrothermal processes in the granite-hosted Zr, Y, REE deposit at Strange Lake, Quebec/Labrador: Evidence from fluid inclusions. Geochimica et Cosmochimica Acta, 1990, vol. 54, no. 9, pp. 2403-2418.

7. Gysi A.P., Williams-Jones A.E. Hydrothermal mobilization of pegmatite-hosted REE and Zr at Strange Lake, Canada: a reaction pathmodel. Geochimica et Cosmochimica Acta, 2013, vol. 122, pp. 324-352.
8. Broom-Fendley S., Heaton T., Wall F., Gunn G. Tracing the fluid source of heavy REE mineralisation in carbonatites using a novel method of oxygen-isotope analysis in apatite: The example of Songwe Hill, Malawi. Chemical Geology, 2016, vol. 440, pp. 275-287.

9. Migdisov A.A., Williams-Jones A.E. A spectrophotometric study of Nd (III), Sm (III) and Er (III) complexation in sulfate-bearing solutions at elevated temperatures. Geochim. Cosmochim. Acta, 2008, vol. 72, pp. 5291-5303.

10. Migdisov A.A., Williams-Jones A.E., Wagner T. An experimental study of the solubility and speciation of the Rare Earth Elements (III) in fluoride- and chloride-bearing aqueous solutions at temperatures up to $300^{\circ} \mathrm{C}$. Geochim. Cosmochim. Acta, 2009, vol. 73, pp. 7087-7109.

11. Migdisov A.A., Williams-Jones A.E. Hydrothermal transport and deposition of the Rare Earth Elements by fluorine-bearing aqueous liquids. Mineral Deposits, 2014, vol. 49, 987-997.

12. Migdisov A., Williams-Jones A.E., Brugger J., Caporuscio F.A. Hydrothermal transport, deposition, and fractionation of the REE: Experimental data and thermodynamic calculations. Chemical Geology, 2016, vol. 439, pp. 13-42.

13. Gysi A.P., Williams-Jones A.E., Harlov D. The solubility of xenotime- $(\mathrm{Y})$ and other HREE phosphates $\left(\mathrm{DyPO}_{4}, \mathrm{ErPO}_{4}\right.$ and $\left.\mathrm{YbPO}_{4}\right)$ in aqueous solutions from 100 to $250{ }^{\circ} \mathrm{C}$ and $p_{\text {sat. }}$. Chemical Geology, 2015, vol. 401, pp. 83-95.

14. Perry E.P., Gysi A.P. Speciation in Hydrothermal Fluids and Partitioning in Calcite. Geofluids, 2018, vol. 2018, pp.1-19.

15. Shironosova G.P., Prokopyev I.R. REE+Y behavior in fluoridechloride-sulphide-sulphate-carbonate environment at hydrother- 
mal stages of alkaline magmatic complexes according to thermodynamic modeling. Bulletin of the Tomsk Polytechnic University. Geo Assets Engineering, 2017, vol. 328, no. 12, pp. 75-83.

16. Shironosova G.P., Prokopyev I.R. Coefficients of distribution of REE $+\mathrm{Y}$ between minerals and cooling rich sulfate fluid. Bulletin of the Tomsk Polytechnic University. Geo Assets Engineering, 2018, vol. 329 , no. 10, pp. 6-18.

17. Haas J.R., Shock E.L., Sassani D.C. Rare earth elements in hydrothermal systems: Estimates of standard partial molal thermodynamic properties of aqueous complexes of the rare earth elements at high pressures and temperatures. Geochim. Cosmochim. Acta, 1995, vol. 59, pp. 4329-4350.

18. Stepanchikova S.A., Biteikina R.P., Shironosova G.P., Kolonin G.R. An experimental study of hydroxo complex formation in basic and near-neutral solutions of rare-earth elements and yttrium at $25^{\circ} \mathrm{C}$. Russian Geology and Geophysics, 2014, vol. 55, pp. $941-944$.
19. Shvarov Yu.V. HCh: New potentialities for the thermodynamic simulation of geochemical systems offered by windows. Geochemistry International, 2008, vol. 46, no. 8, pp. 834-839.

20. Shvarov Yu.V., Bastrakov E. HCh: a Software Package for Geochemical Equilibrium Modeling: User's Guide (AGSO RECORD, 1999). Canberra, Dept. Industry, Australian Geol. Surv. Org., Sci. Resour., 1999. 57 p.

21. Gysi A.P., Williams-Jones A.E. The thermodynamic properties of bastnasite-(Ce) and parisite-(Ce). Chemical Geology, 2015, vol. 392, pp. 87-101.

22. Schmandt D.S., Cook N.J., Ciobanu C.L., Ehrig K., Wade B.P., Gilbert S., Kamenetsky V.S. Rare earth element fluorocarbonate minerals from the Olympic Dam Cu-U-Au-Ag deposit, South $\mathrm{Au}-$ stralia. Minerals, 2017, vol. 7, pp. 202. DOI: $10.3390 / \min 7100202$.

Received: 16 October 2018.

\section{Information about the authors}

Galina P. Shironosova, Cand. Sc., senior researcher, V.S. Sobolev Institute of Geology and Mineralogy SB RAS.

Ilya R. Prokopyev, Cand. Sc., senior researcher, V.S. Sobolev Institute of Geology and Mineralogy SB RAS; senior lector, Novosibirsk State University. 